\title{
Uncooled Thin Film Infrared Imaging Device with Aerogel Thermal Isolation:
}

\section{Deposition and Planarization Techniques

J. A. Ruffnera, P. G. Clemª , B. A. Tuttle ${ }^{a}$, C. J. Brinker ${ }^{a}$, C . S. Sriram ${ }^{b}$, J. A. Bullington ${ }^{c}$

- Sandia National Laboratories MS 1349, P. O. Box 5800, Albuquerque, NM 87185-1349

${ }^{b}$ Department of Chemical and Nuclear Engineering, The University of New Mexico, Albuquerque, NM 87131

' AMMPEC, Inc., 7804-3 Pan American Freeway, Albuquerque, NM 87109

\section{Abstract}

\section{DTIC QUALTTY INSPECTED}

We have successfully integrated a thermally insulating silica aerogel thin film into a new uncooled monolithic thin film infrared (IR) imaging device. Compared to other technologies (bulk ceramic and microbridge), use of an aerogel layer provides superior thermal isolation of the pyroelectric imaging element from the relatively massive heat sinking integrated circuit. This results in significantly higher thermal and temporal resolutions. We have calculated noise equivalent temperature differences of $0.04-0.10^{\circ} \mathrm{C}$ from a variety of $\mathrm{Pb}_{x} \mathrm{Zr}_{y} \mathrm{Ti}_{1-\mathrm{y}} \mathrm{O}_{3}(\mathrm{PZT})$ and $\mathrm{Pb}_{\mathrm{x}} \mathrm{La}_{1-\mathrm{x}} \mathrm{Zr}_{\mathrm{y}} \mathrm{Ti}_{1-\mathrm{y}} \mathrm{O}_{3}$ (PLZT) pyroelectric imaging elements in monolithic structures. In addition, use of aerogels results in an easier, less expensive fabrication process and a more robust device.

Fabrication of these monolithic devices entails sol-gel deposition of the aerogel, sputter deposition of the electrodes, and solution chemistry deposition of the pyroelectric imaging elements. Uniform pyroelectric response is achieved across the device by use of appropriate planarization techniques. These deposition and planarization techniques are described. Characterization of the individual layers and monolithic structure using scanning electron microscopy, atomic force microscopy and Byer-Roundy techniques also is discussed.

Sandia is a multiprogram laboratory operated by Sandia Corporation, a Lockheed Martin Company, for the United States Department of Energy under Contract DE-AC04-94AL85000. .

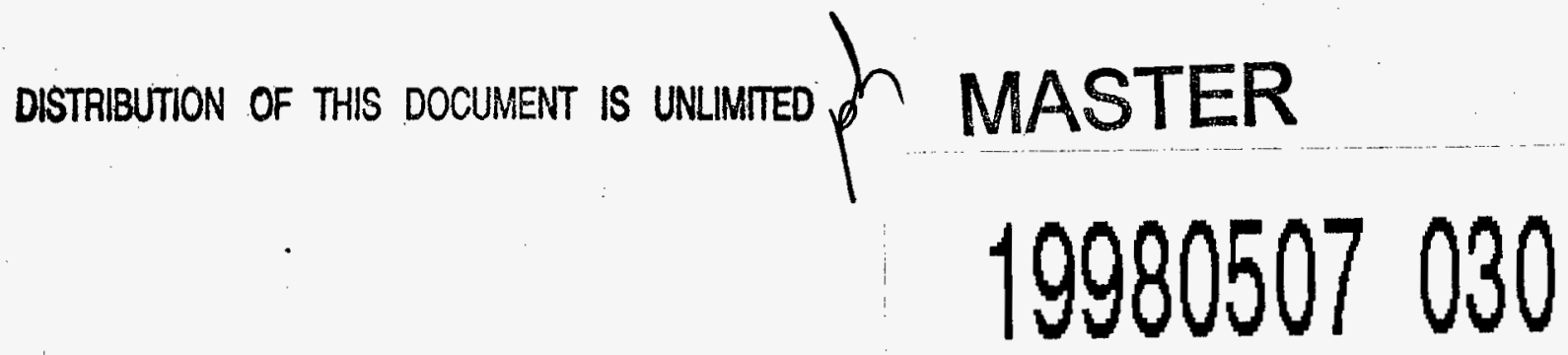




\section{DISCLAIMER}

This report was prepared as an account of work sponsored by an agency of the United States Government. Neither the United States Government nor any agency thereof, nor any of their employees, makes any warranty, express or implied, or assumes any legal liability or responsibility for the accuracy, completeness, or usefulness of any information, apparatus, product, or process disclosed, or represents that its use would not infringe privately owned rights. Reference herein to any specific commercial product, process, or service by trade name, trademark, manufacturer, or otherwise does not necessarily constitute or imply its endorsement, recommendation, or favoring by the United States Government or any agency thereof. The views and opinions of authors expressed herein do not necessarily state or reflect those of the United States Government or any agency thereof. 


\section{Introduction}

Uncooled pyroelectric IR imaging systems, such as night vision goggles, offer important strategic advantages in battlefield scenarios and reconnaissance surveys. Inexpensive uncooled IR imaging arrays also would be useful in commercial applications such as emergency (fire) rescue equipment, medical imaging systems, security surveillance systems, and imaging systems for cars, ships and aircraft.

Pyroelectric detectors offer excellent performance at room temperature and do not require cooling. They are suitable for small, light-weight detection systems that are reliable and require minimal power. Unfortunately, these detectors have been difficult and costly to fabricate. The pyroelectric detectors that are presently available consist of a laser-reticulated barium strontium titanate (BST) ceramic that is flat-lapped to a thickness of $<20 \mu \mathrm{m}$ and then indium bump-bonded to an integrated circuit [1]. This difficult fabrication process results in low yield, high cost and limited spatial resolution ( $48 \mu \mathrm{m}$ pixel size).

Our new monolithic pyroelectric imaging device is shown schematically in Figure 1 [2, 3]. A silica aerogel thin film is deposited in order to provide effective thermal isolation between an oxidized silicon substrate and the overlying pyroelectric imaging element. The thermal isolation enables the pyroelectric element to achieve the maximum thermal and temporal resolution for the imaging device. An etch stop layer is then deposited to enable subsequent processing into a 2dimensional array. This is followed by deposition of a bottom electrode stack, thin film pyroelectric imaging element, and top electrode. Finally a blacking layer is deposited to enable the conversion of thermal radiation at the appropriate wavelengths into a heat signal $(\Delta \mathrm{T})$.

Recently, Prakash et al. demonstrated aerogel thin film deposition, whereby $0.4-2 \mu \mathrm{m}$ thickness silica aerogel films with up to $98 \%$ porosity may be rapidly deposited onto silicon wafers $[4,5]$. The thermal conductivity of an aerogel has been shown to decrease linearly as porosity increases [6]. For porosity levels of $75-98 \%$, silica aerogels offer better thermal insulation than stagnant air which is used as the thermal insulation material in self-support microbridge structures 
$[7,8,9]$. In addition, our monolithic stack is more robust and easier to fabricate than the microbridge structures.

Compared to commercially available bulk BST imaging elements, the thin film pyroelectric imaging element in our monolithic device is much thinner ( $\leq 1 \mu \mathrm{m}$ compared to $20 \mu \mathrm{m}$ ) and has a lower thermal mass [1]. This results in 20-50 times faster response times and larger voltage responses. The noise equivalent temperature difference (NETD) of the present detector is $0.07{ }^{\circ} \mathrm{C}$ compared to $0.1{ }^{\circ} \mathrm{C}$ in the BST device, indicating a $43 \%$ increase in the signal-to-noise ratio.

The fully integrated design of the present monolithic uncooled IR detector should enable mass production using semiconductor processing technology. This should result in excellent spatial resolution ( $4 \mu \mathrm{m}$ pixel size) at a greatly reduced cost (estimated at $\$ 10-50 /$ array).

\section{Experiment}

\section{Integrated Device Considerations}

There were a number of material and processing issues that were considered prior to design and fabrication of this monolithic structure. In particular, the porous nature of the aerogel thin film must be preserved. Therefore, all processing performed after deposition of the aerogel took place at temperatures that would not cause the aerogel's silica framework to densify and collapse ( $\mathrm{T}<$ $600^{\circ} \mathrm{C}$ ). Next, an intermediate sputter deposition step was performed to seal the top surface of the aerogel and prevent permeation of solutions used for subsequent depositions into the aerogel.

Finally, the aerogel surface was made sufficiently smooth by developing appropriate deposition and planarization techniques for the aerogel, electrode stack and pyroelectric element.

\section{Development of Aerogels}

Silica aerogel thin films were deposited by dip coating and spin coating onto thermally oxidized silicon wafers, following the procedure described in detail elsewhere $[2,4,5]$. A siliconbased aerogel was chosen for this application because of its similar chemistry to the Si used for the integrated circuitry. 
Briefly, the preparation of the aerogel thin films consists of the following steps:

1) Preparation of the chemical solution - Stock solution, ethanol and a base catalyst are mixed together.

2) Preparation of the gel $-\mathrm{NH}_{4} \mathrm{OH}$ is added to promote gelation.

3) Pore fluid exchange - The gel is washed thoroughly.

4) Surface derivatization - The gel is soaked in trimethylchlorosilane (TMCS) in hexane and then washed.

5) Sonication - The gel is ultrasonicated to redisperse sol.

6) Spin- and dip-coating depositions - Oxidized silicon wafers are coated with sol.

7) Pyrolyzing the aerogel thin film - Thin film is pyrolyzed at $450^{\circ} \mathrm{C}$ for one hour.

The thicknesses and refractive indices of the aerogel films were measured using a Gaertner L116C ellipsometer. The volume porosity was calculated from the refractive indices using the Lorentz-Lorenz equation. Thickness values for preliminary samples were verified using a Hitachi S-4500 field emitter scanning electron microscope, while a Nanoscope II atomic force microscope (AFM) was used to characterize the surface structure of the aerogel thin films.

\section{Planarization of the Aerogel Surface}

The aerogel surface must be sufficiently smooth so that overlying layers are continuous and uniform in thickness. Three different techniques were used to minimize the roughness within the stack: modifying the aerogel deposition conditions, planarizing the aerogel surface using sputter deposition techniques, and planarizing the stack using solution chemistry deposition.

First, the deposition conditions of the aerogel layer itself were modified to reduce roughness. Initial attempts at deposition of the aerogel thin film using dip-coating techniques resulted in a ribbed pattern in which striations of variable thickness ran perpendicular to the direction of pull. In order to avoid this, we used a lower volatility solvent, heptane, instead of hexane in the surface derivatization and all subsequent steps. In addition, spin-coating was used in place of dip-coating for all subsequent aerogel films. 
Second, a variety of sputter deposition techniques were used in an attempt to deposit a smooth thin film coating onto the relatively rough aerogel surface. $\mathrm{TiO}_{2}$ was chosen as the planarization layer because of its chemical compatibility with silica and its effectiveness as an etch stop layer for subsequent device processing. Three different thicknesses (100, 500 and 1,000 nm) of $\mathrm{TiO}_{2}$ layers were deposited in order to test the effect of thickness on the rms surface roughness. In addition, $\mathrm{TiO}_{2}$ films were deposited onto biased substrates $(0,-75$, and $-150 \mathrm{VDC})$ in an attempt to form smooth films on the relatively rough aerogel surface. Biasing the substrate causes loosely bound atoms (e.g. those on a sloped surface) to be ejected, or resputtered, from the thin film surface [10]. This has the effect of covering steps and planarizing a rough surface as film growth proceeds.

The planarization layers were sputter deposited onto silica aerogel films using previously described parameters [3] in a UniFilm PVD-300 Multi-Source Sputter System with a base pressure of $4 \times 10^{-5} \mathrm{~Pa}$. The aerogel thin films were heated to $250^{\circ} \mathrm{C}$ in vacuum for one hour prior to deposition in order to drive off water from the porous aerogel structure and to enhance adhesion of the overlying sputtered coatings. The planarization layer and bottom electrode stack consisting of titanium/platinum/ and $\mathrm{La}_{0.5} \mathrm{Sr}_{0.5} \mathrm{CoO}_{3}$ (LSCO) then were deposited at ambient temperature. The rms surface roughness of the resultant layers was measured using an AFM.

Finally, the solution deposition of the pyroelectric imaging elements was used to fill the low spots in the monolithic structure, thereby planarizing its surface. Following the concept of other solution-deposition work used to planarize rough surfaces [11], multiple thin coatings of PZT were deposited by use of more dilute $0.1 \mathrm{M}$ solutions. Individual layers were heated on a hot plate to $300{ }^{\circ} \mathrm{C}$ between depositions, and crystallized by heating to $550^{\circ} \mathrm{C}$ for 30 minutes after every $3-4$ layers.

\section{Deposition and Testing of Pyroelectric Imaging Elements}

Integrated ferroelectric thin films possess high pyroelectric coefficients and small thermal masses which make them attractive for infrared imaging applications [12, 13]. The pyroelectric imaging element used in these devices was selected on the basis of its pyroelectric response over 
the operational temperature range $\left(\sim 0-40^{\circ} \mathrm{C}\right)$ of the sensor. Lead zirconate titanate (PZT: $\mathrm{Pb}_{\mathrm{x}} \mathrm{Zr}_{\mathrm{y}} \mathrm{Ti}_{1-\mathrm{y}} \mathrm{O}_{3}$ ) and lead lanthanum zirconate titanate (PLZT: $\mathrm{Pb}_{\mathrm{x}} \mathrm{La}_{1-\mathrm{x}} \mathrm{Zr}_{\mathrm{y}} \mathrm{Ti}_{1-\mathrm{y}} \mathrm{O}_{3}$ ) were the materials of choice. The pyroelectric response of these materials can be optimized by adjusting the composition, and both can be pyrolyzed at temperatures that do not adversely affect the underlying silica aerogel thin film $\left(\mathrm{T}<600^{\circ} \mathrm{C}\right)$. PZT and PLZT compositions offer good pyroelectric responses and have been investigated extensively [14].

PZT thin films were deposited by solution deposition using a method described by Schwartz et al. [15]. Solutions of $0.4 \mathrm{M}$ concentration were spin coated at $3000 \mathrm{rpm}$ onto substrates such as platinized silicon. It was possible reproducibly to deposit $100 \mathrm{~nm}$ thick high quality PZT films. For deposition on the electroded aerogels, however, modifications were necessary to address film stress and electrode smoothness issues. Typically, multiple layers of 0.1 M solutions were spin coated on the electroded aerogel substrates, with hot plate treatments to 300 ${ }^{\circ} \mathrm{C}$ between each layer, and crystallization at $550^{\circ} \mathrm{C}$ for 30 minutes every third layer. Films of 100 $400 \mathrm{~nm}$ thickness were produced by repeating this cycle.

Samples then were electrically characterized for dielectric and ferroelectric properties using a Hewlett Packard 4284A precision LCR meter and a Radiant Technologies RT-66A test unit, respectively. Pyroelectric measurements were obtained using the Byer-Roundy method, using a computer-controlled Signatone hot stage for linear heating and cooling ramp rates, and a Keithley 236 source measure unit to monitor current. Samples were poled at $300 \mathrm{kV} / \mathrm{cm}$ for 30 seconds, and held 15 minutes after poling before pyroelectric measurement. Pyroelectric measurements were repeated three times on heating and cooling to avoid any current transients associated with the film poling process. From these measurements, the noise equivalent temperature difference (NETD) of an imaging array was calculated $[16,17]$. NETD is defined as the thermal signal required to equal the inherent electronic noise in a detector (i.e. signal-to-noise ratio $=1$ ). For device applications, high sensitivity may be expressed as a low NETD.

\section{Results and Discussion}




\section{Performance and Planarization of the Aerogel Surfaces}

The adhesion of the silica aerogel thin films to the underlying oxidized silicon wafer was highly dependent upon the initial substrate cleaning procedure. Oxidized silicon wafers that were simply rinsed in a stream of ethanol for one minute prior to aerogel deposition would delaminate at the aerogel/substrate interface during the subsequent anneal of LSCO to $550^{\circ} \mathrm{C}$. Cleaning the oxidized wafers in a UV ozone oven for 30 minutes prior to aerogel deposition greatly improved adhesion and survivability during all subsequent processing steps in this monolithic thin film structure.

The aerogel films deposited using heptane are uniform in thickness with a maximum variation of about $10 \%$. They are completely free of visible striations and AFM analysis indicates that the rms roughness is $\leq 10 \mathrm{~nm}$ for these films. A typical aerogel surface is shown in Figure 2a. They are $\sim 0.8 \mu \mathrm{m}$ thick with a porosity of approximately $83 \%$. More recently, researchers have developed a new surface derivatization process using hexamethyldisilazane instead of TMCS in the surface derivatization step which results in thicker and more uniform aerogel films with porosities of $90 \%$. The microstructure of aerogels deposited using the new process is shown in Figure $2 \mathrm{~b}$. Although the rms surface roughness is higher than for those deposited using TMCS (18.6 nm compared to $8.1 \mathrm{~nm}$ ), the greater thicknesses, higher porosities and better overall large-scale uniformity across the wafer make this a promising new technique for aerogel deposition [18].

We were able to sputter deposit multilayered thin film stacks directly on top of silica aerogel thin films. The sputter-deposited planarization, adhesion, and electrode layers effectively sealed the porous top surface of the aerogel and enabled subsequent solution chemistry deposition of the pyroelectric imaging element. To our knowledge, this represents the first successful integration of aerogel films with these two other deposition techniques. The resultant monolithic structures proved to be robust for processing temperatures of up to $550^{\circ} \mathrm{C}$.

$\mathrm{TiO}_{2}$ thin films of various thicknesses and processing conditions were deposited directly onto aerogel layers in order to determine their effectiveness at sealing and planarizing the aerogel 
surface. The resultant rms surface roughnesses for the planarization and overlying platinum and LSCO layers are summarized in Table I.

The measured rms surface roughnesses of all aerogel films were nearly equal as expected. The surface roughness of the $\mathrm{TiO}_{2}$ planarization layer was found to be highly dependent upon its thickness. Increasing the thickness from 100 to $1,000 \mathrm{~nm}$ resulted in over twice the rms roughness (from $9.7 \mathrm{~nm}$ to $22.3 \mathrm{~nm}$ ). Applying a bias voltage (-75 VDC) to the substrate significantly reduced the roughness of the much thicker samples (from $22.3 \mathrm{~nm}$ down to $9.3 \mathrm{~nm}$ ). Increasing the bias voltage to -150 VDC did not reduce the roughness further, suggesting that charging of the substrate may have occurred for the higher bias voltage. The surface roughness of the uppermost LSCO layer was found to be $\sim 10 \mathrm{~nm}$ for most samples measured over a $20 \times 20 \mu \mathrm{m}$ scan area. While sputter deposition of the $\mathrm{TiO}_{2}$ layer, even onto a biased substrate, did not reduce the overall surface roughness significantly, it did result in a sufficiently smooth surface for subsequent solution chemistry deposition of the pyroelectric imaging element. In addition, sputter deposition of the $\mathrm{TiO}_{2}$ layer and bottom electrode layers effectively sealed the aerogel layer, thereby preventing permeation of the PZT and PLZT solutions into the porous aerogel structure.

In spite of the low rms surface roughness, the LSCO//Pt//aerogel//Si substrates appeared to exhibit longer-range surface roughness as suggested by diffuse reflection of background light. Initial use of $0.4 \mathrm{M}$ solutions to deposit 100-400 nm PZT layers on the electroded aerogels gave rise to low yields and extensive shorting of PZT film capacitors. Following the concept of other solution-deposition work used to planarize rough surfaces [11], multiple thin coatings of PZT were deposited by use of more dilute solutions. The resultant PZT thin films exhibited little specular scattering, and displayed $80-100 \%$ pixel yield as a result of increased uniformity.

\section{Performance of Pyroelectric Imaging Elements}

A composite $\mathrm{PZT} / / \mathrm{LSCO} / / \mathrm{Pt} / /$ aerogel//silicon structure was fabricated by this process. A $0.4 \mathrm{~mm}$ thick PZT film was produced by firing at $550^{\circ} \mathrm{C}$ for 30 minutes on the electroded $0.4 \mu \mathrm{m}$ aerogel film. The PZT film is characterized by a $0.3 \mu \mathrm{m}$ grain size and appears to be single phase 
$\mathrm{Pb}\left(\mathrm{Zr}_{0.4} \mathrm{Ti}_{0.6}\right) \mathrm{O}_{3}$, without evidence of pyrochlore or fluorite phases. The fine grain size suggests monodomain PZT grains may result, which would be advantageous if orientation can be controlled.

Ferroelectric properties of these thin films on LSCO//Pt//aerogel//Si substrates were compared with identically -processed PZT layers deposited on LSCO//Pt/Si substrates and $\mathrm{LSCO} / \mathrm{Pt} / \mathrm{MgO}$ substrates to gain an understanding of substrate stress effects on ferroelectric properties $[19,20]$. We observed that PZT films deposited on high thermal expansion coefficient oxide substrates such as $\mathrm{MgO}$ and $\mathrm{Al}_{2} \mathrm{O}_{3}$ are in compressive stress on cooling to room temperature, inducing c-axis orientation and square hysteresis loops with a large $\mathrm{P}_{\mathrm{r}}$ as shown in Figure 3. In contrast, films deposited on platinized silicon substrates are typically in tensile stress, resulting in aaxis orientation and flatter hysteresis loops. It was hoped in the current research that use of an aerogel thin film might elastically decouple the PZT film from the underlying silicon substrate, resulting in enhanced ferroelectric and pyroelectric properties. The hysteresis loop for the aerogelcoated silicon substrate shown in Figure 3 indicates an intermediate ferroelectric response. While some modest stress decoupling may be responsible for the shape of the hysteresis loop on the aerogel, the overall shape is more akin to PZT in tensile stress on silicon. Thin film x-ray diffraction indicated the film to be dominantly a-axis oriented atop the aerogel, further confirming this possibility.

Pyroelectric measurements were obtained for a variety of PZT-based compositions on platinized silicon and $\mathrm{MgO}$, and for $\mathrm{Pb}\left(\mathrm{Zr}_{0.4} \mathrm{Ti}_{0.6}\right) \mathrm{O}_{3}$ on the aerogel structure. Pyroelectric measurements $(p)$, voltage figures of merit $\left(F_{v}\right)$ and calculated NETD values for several compositions are shown in Table II. Films of $\mathrm{Pb}\left(\mathrm{Zr}_{0.4} \mathrm{Ti}_{0.6}\right) \mathrm{O}_{3}$ on the electroded aerogel displayed a pyroelectric coefficient of $30 \mathrm{nC} / \mathrm{cm}^{2} \mathrm{~K}$, and a calculated NETD of $0.07^{\circ} \mathrm{C}$, assuming $\mathrm{f} / 1.0$ optics, $\mathrm{G}=5 \times 10^{8} \mathrm{~W} / \mathrm{K}$ thermal conductance, and a $50 \mu \mathrm{m}$ pixel size. The thermal conductance value used, typical of air-gap structures, is probably conservative, since aerogels potentially offer even lower thermal conductivity. Several other PZT compositions appear to show promise for achieving similar NETD values as well.

\section{Conclusions}


We have fabricated several monolithic structures for uncooled infrared imaging that utilize silica aerogel thin films as thermal isolation layers. To our knowledge, this is the first reported successful integration of other deposition processes (sputtering and solution chemistry) with an aerogel thin film. The resultant monolithic structures showed excellent pyroelectric response with an NETD value of $0.7{ }^{\circ} \mathrm{C}$. This represents a $43 \%$ increase in the signal-to-noise ratio offered by commercially-available uncooled infrared imaging systems. In addition, the ability to fabricate this device using standard thin film deposition techniques and to process the device into a fully integrated 2-dimensional imaging array using standard semiconductor techniques promises to reduce the cost and increase commercial availability of these sensors dramatically.

We gratefully acknowledge Bonnie McKenzie, Sandia National Laboratories, for the scanning electron microscopy analysis. 


\section{References}

[1] C. M. Hanson, K. N. Sweetser, and S. N. Frank, "Uncooled Thermal Imaging," Texas Instruments Technical Journal 11 (Sept.-Oct., 1994) 2.

[2] J. A. Ruffner, J. A. Bullington, P. G. Clem, W. L. Warren, C. J. Brinker, B. A. Tuttle, and R. W. Schwartz, Sandia National Laboratories SD-5782, U. S. Patent Application, (1997).

[3] J. A. Ruffner, P. G. Clem, B. A. Tuttle, C. J. Brinker, W. L. Warren, R. W. Schwartz, M. V. Raymond, H. N. Al-Shareef, D. M. Mortimer, R. D. Nasby, A. J. Hurd, T. L. Reichert, C. S. Sriram, R. Bhatia and J. A. Bullington, Sandia Report SAND98-0138, Sandia National Laboratories (1998).

[4] S. S. Prakash, C. J. Brinker, A. J. Hurd, and S. Rao, Nature 374 (1995) 439.

[5] S. S. Prakash, C. J. Brinker, and A. J. Hurd, J. Non-Cryst. Solids, 190 (1995) 264.

[6] P. Scheuerpflug, M. Hauck and J. Fricke, J. Non-Cryst. Solids 145 (1992) 196.

[7] D. L. Polla, T. Tamagawa, C. Ye, P. Schiller, L. Pharm and C. Y. Tu, SPIE Proc. 1694 (1992) 173.

[8] H. R. Beratan and C. M. Hanson, Texas Instruments, Inc., U. S. Patent 5,602,043 (1997).

[9] G. B. Hocker, J. O. Holmen, and R. G. Johnson, Honeywell, Inc., U. S. Patent 5,534,111 (1996).

[10] T. N. Kennedy, J. Vac. Sci. Technol., 13 (1976) 1135.

[11] A. S. Holmes, R. R. A. Syms, M. Li and M. Green, Applied Optics 32 (1993) 4916.

[12] B. A. Tuttle, P. G. Clem, J. A. Ruffner, M. A. Rodriguez, D. R. Tallant, D. Dimos, and C. J. Brinker, Workshop of the COST 514EU Action on Ferroelectric Thin Films, Parma, Italy (1997).

[13] B. A. Tuttle, H. N. Al-Shareef, J. A. Ruffner, C. J. Brinker, T. J. Garino, and D. Dimos, American Ceramic Society Conference, San Antonio, TX (1996).

[14] K. K. Deb, K. W. Bennett, and P. S. Brody, J. Vac. Sci. Technol. A 13 (1995) 1128.

[15] R. W. Schwartz, R. A. Assink, and T. J. Headley, Ferroelectric Thin Films II, Mat. Res. Soc. Symp. Proc. 361 (1995) 377. 
[16] B. M. Kulwicki, A. Amin, H. R. Beratan, and C. H. Hanson, Proc. 8th IEEE ISAF, (1992) 1 .

[17] P. W. Kruse, Proc. 9th IEEE ISAF, (1994) 643.

[18] C. S. Sriram, C. J. Brinker and K. Vanheusden, to be published, (1998).

[19] P. G. Clem, B. A. Tuttle, J. A. Ruffner, C. J. Brinker, R. W. Schwartz, M. Rodriguez, and W. L. Warren, Integrated Ferroelectrics, (1997) in press.

[20] P. G. Clem, B. A. Tuttle, J. A. Ruffner, C. J. Brinker, R. W. Schwartz, M. A.

Rodriguez, and W. L. Warren, 9th Annual Symposium on Integrated Ferroelectrics, Santa Fe, NM, (1997). 
Table I: rms surface roughness values for various layers within multilayered structure for different planarization layers.

\begin{tabular}{|c|c|c|c|c|c|}
\hline $\begin{array}{c}\text { Planarization } \\
\text { layer } \\
(\mathrm{nm} \mathrm{TiO}\end{array}$ & $\begin{array}{c}\text { Bias voltage } \\
(\mathrm{VDC})\end{array}$ & $\begin{array}{c}\text { Aerogel rms } \\
\text { roughness } \\
(\mathrm{nm})\end{array}$ & $\begin{array}{c}\text { Planarization } \\
\text { layer rms } \\
\text { roughness (nm) }\end{array}$ & $\begin{array}{c}\text { Pt rms } \\
\text { roughness } \\
(\mathrm{nm})\end{array}$ & $\begin{array}{c}\text { LSCO rms } \\
\text { roughness } \\
(\mathrm{nm})\end{array}$ \\
\hline 100 & 0 & 11.1 & 9.7 & 8.9 & 10.3 \\
\hline 500 & 0 & -11 & & 8.9 & 9.4 \\
\hline 1,000 & 0 & 11.6 & 22.3 & 23.2 & 26.7 \\
\hline 1,000 & -75 & 13.7 & 9.3 & & 10.9 \\
\hline 1,000 & -150 & 11.9 & 10.3 & & 10.6 \\
\hline
\end{tabular}


Table II: Measured PZT-based thin film pyroelectric values

Thin film substrate $\quad \underline{\mathrm{p}\left(\mu \mathrm{C} / \mathrm{cm}^{2} \mathrm{~K}\right)} \quad \underline{\mathrm{F}}_{\mathrm{x}}\left(\mathrm{cm}^{2} / \mathrm{C}\right) \quad$ NETD(calculated)

PZT $85 / 15$

PZT 30/70

PLZT 4/50/50

PLZT $3 / 30 / 70$

PTaZT 4/50/50

PLZT 5/30/70

PZT 40/60

LSCO/Pt/aerogel/Si

$\mathrm{Pt} / \mathrm{Si}$

$\mathrm{Pt} / \mathrm{Si}$

$\mathrm{Pt} / \mathrm{Si}$

$\mathrm{Pt} / \mathrm{Si}$

$\mathrm{Pt} / \mathrm{Si}$

0.034

0.040

0.060

0.064

0.071

0.030

95

184

196

272

313

475

219

$0.17^{\circ} \mathrm{C}$
$0.09^{\circ} \mathrm{C}$
$0.08^{\circ} \mathrm{C}$
$0.06^{\circ} \mathrm{C}^{*}$
$0.05^{\circ} \mathrm{C}$
$0.04^{\circ} \mathrm{C}^{*}$
$0.07^{\circ} \mathrm{C}$

* measured on first heating of film 


\section{Figure Captions}

Figure 1: Schematic of monolithic uncooled infrared imaging device with silica aerogel thermal isolation layer.

Figure 2: Scanning electron micrographs of silica aerogel films deposited using (a) TMCS (rms

surface roughness $=8.1 \mathrm{~nm})$ and $(\mathrm{b})$ hexamethyldisilazane $(\mathrm{rms}$ surface roughness $=18.6 \mathrm{~nm})$ for surface derivatization.

Figure 3: Hysteresis loops for $200 \mathrm{~nm}$ PZT 40/60 on LSCO//Pt/substrate for MgO, aerogel, and Si substrates. 
Figure 1

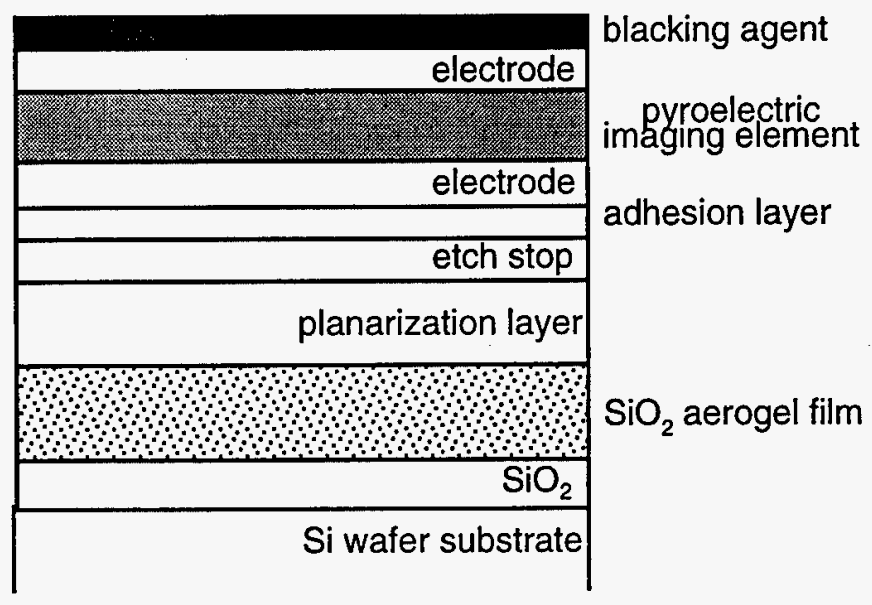



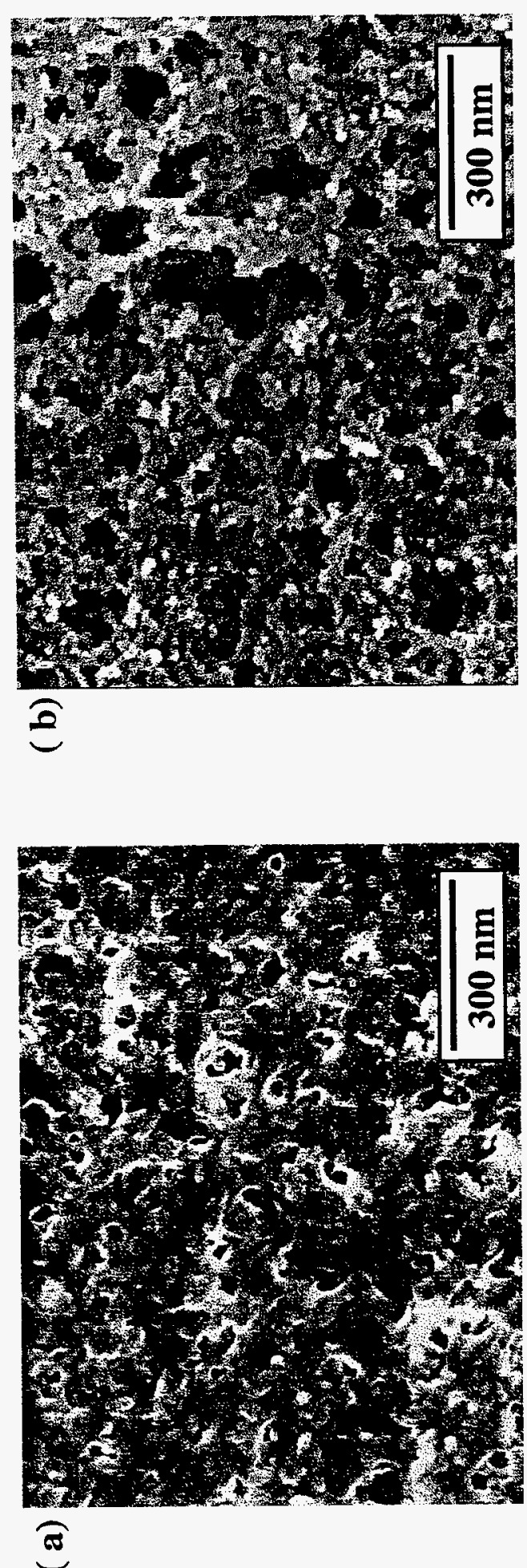
Figure 3

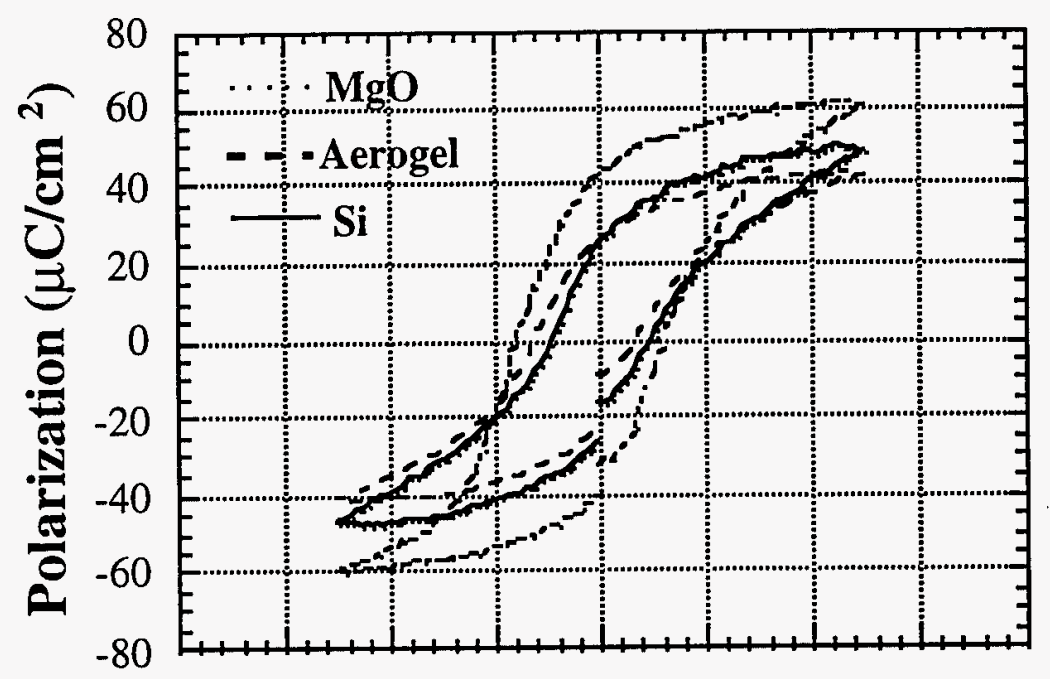

Voltage (V) 
Report Number (14)SAND--98-0847C CONF-980429--

Publ. Date (11) $\frac{199804}{\text { SOE/CR, XF }}$
$\begin{aligned} & \text { Sponsor Code (18) } \\ & \text { UC Category (19) }\end{aligned}$ 